\section{Publishing for conservation and development?}

I was not part of the Madagascar Conservation \& Development (MCD) team when it was launched in 2006; indeed, I was not even aware that such a journal was in the pipeline. So, like many others, I was very excited to read the first issue: here, at last, was a modern journal - online, open access, bilingual, transdisciplinary - to meet Madagascar's emerging information needs as it implements its ambitious Durban Vision and struggles to cope with increasingly urgent environmental and development challenges. Launched as a "(...) forum for the exchange of experiences and knowledge (...)" (Waeber and Hänni 2006: 2), I felt that the journal offered a real opportunity for researchers and practitioners to contribute to the development of the country and conservation of its unique biodiversity. As we publish our 100th peer-reviewed contribution in this, our 15th issue, it is pertinent to reflect on how well this resource is being put to use by the country's conservation and development community.

For a scientific journal to make a tangible contribution to conservation, it must make efforts to overcome the 'researcherpractitioner divide' - an increasingly-recognised phenomenon that limits the utility of science to the real-world practice of conserving biodiversity. The divide manifests itself in numerous ways: conservation practitioners do not tend to read the latest literature or make use of its findings to inform their actions, at least in part because they don't have access to it, and because they are too busy fighting fires (literally and figuratively) in their day-to-day jobs (Pullin and Knight 2005, Cook et al. 2010). Most researchers, in turn, rarely consider practitioners' information needs when developing their research agendas - since their motivation is to publish in high impact international journals, they tend to focus on sophisticated analyses of global relevance rather than the local case studies that conservationists need to inform their work (Arlettaz et al. 2010, Hulme 2011). The result is the publication of vast quantities of conservation-related research that is only peripherally relevant to the practice of conservation (Smith et al. 2009, Milner-Gulland et al. 2010); it tells us how urgent the threats are and where we should focus our efforts, among other things, but only rarely advises us of 'how' to go about reversing the observed trends. Even when research of practical use is produced, its authors do not necessarily share it with those who could use it (Gardner 2012).

MCD offers several ways to start bridging this researcherpractitioner divide. As an open access journal, its articles are freely available to download and thus accessible to anybody with an internet connection - most international journals are hidden behind expensive paywalls, their subscriptions only affordable to well-funded academic institutions. MCD papers can be freely shared because they are published under a Creative Commons license, but this practice is not permitted by many other publishers (see http://www.sherpa.ac.uk/romeo/).
By publishing in French as well as English, MCD also minimises the language barrier that places most of the research carried out in Madagascar beyond the reach of much of its potential audience. In doing so, it also provides an opportunity for those Malagasy and francophone researchers who lack the necessary linguistic skills for international publication to ensure that their work gets out into the public domain. Since only $17 \%$ of MCD's contributions so far have been published in French it is clear that this opportunity has not yet been fully exploited, although an encouraging $53 \%$ of contributions have featured a Malagasy author and $34 \%$ had a Malagasy first author.

To my mind, however, the greatest potential of MCD to bridge the divide and contribute to conservation stems from its position as a forum for the exchange of experiences. Most scientific journals, at least those in the fields of applied ecology and conservation biology with which I'm most familiar, focus on the exchange of knowledge and, in particular, ways of generating knowledge (i.e. 'clever new methods'): these journals are concerned with 'science', and the more sophisticated and groundbreaking it is the better. In the real world, however, conservation practice is rarely driven by science; instead it is usually implemented through trial and error, informed by intuition and anecdote. This means that practitioners are in possession of a huge body of experiential knowledge - an understanding of what worked, what didn't, and what factors influenced the success or failure of their actions - that provides an invaluable complement to scientific knowledge (Fazey et al. 2006), yet these experiences are rarely shared except face-to-face.

Encouraging practitioners to share their experiences is essential if we are to make conservation more effective (Sunderland et al. 2009) - it allows us to learn from each other's efforts, avoid repeating the same mistakes, and start developing best practice. As such, I have found the most interesting and useful articles in MCD to be those in which practitioners have shared lessons learned from their experiences of implementing conservation actions on the ground. These include Harris (2007), Rabearivony et al. (2008), and Richard and Ratsirarson (2013), which provide insights from the establishment and management of Velondriake, Manambolomaty and Bezà Mahafaly protected areas respectively, and whose experiences are highly relevant to the managers of co-managed protected areas in Madagascar and across the world. What's more, such experiential papers give researchers an insight into the information needs of conservation actors, allowing them to develop more relevant research agendas.

As useful as they are, these types of contributions rarely feature in the peer-reviewed literature - practitioners seldom write them because they are not rewarded for doing so by their employers, and international journals tend to shun them because, being anecdotal and failing to test any hypotheses, they are not seen as sufficiently scientific. What's more, since they are local rather than global in scope, editors fear that they will not generate sufficient citations to keep their journals at the top of the rankings in their field. Some journals recognise this failing and provide a special forum for these exchanges - such as 'Practitioner's Perspectives' in Journal of Applied Ecology or 'Conservation Practice and Policy' in Conservation Biology, but opportunities to share experiences in the literature remain marginal.

Not so in Madagascar. With its transdiciplinary scope and the primacy it places on advancing conservation and develop- 


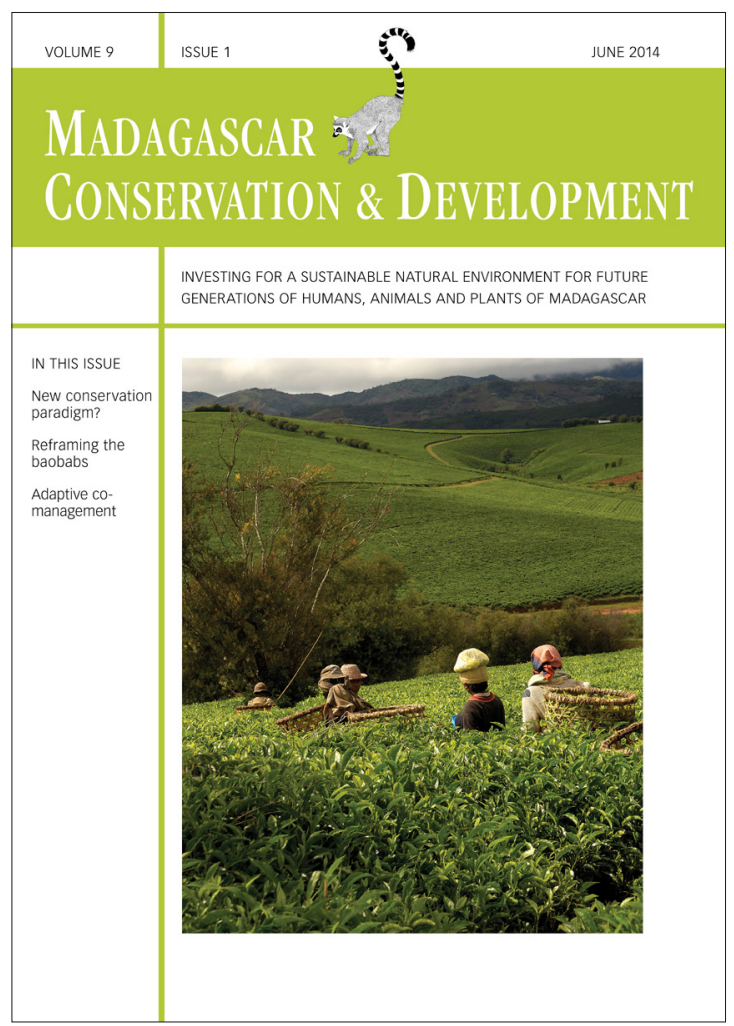

Madagascar Conservation \& Development is the journal of Indian Ocean e-Ink. It is produced under the responsibility of this institution. The views expressed in contributions to MCD are solely those of the authors and not those of the journal editors or the publisher.

All the Issues and articles are freely available at http://www.journalmcd.com

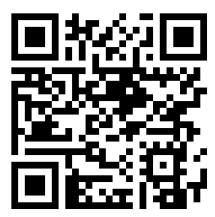

Contact Journal MCD

info@journalmcd.net for general inquiries regarding MCD funding@journalmcd.net to support the journal

Madagascar Conservation \& Development Institute and Museum of Anthropology University of Zurich

Winterthurerstrasse 190

$\mathrm{CH}-8057$ Zurich

Switzerland

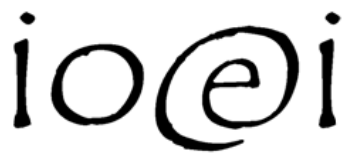

Indian Ocean e-Ink

Promoting African Publishing and Education www.ioeink.com

Missouri Botanical Garden (MBG)

Madagascar Research and Conservation Program BP 3391

Antananarivo, 101, Madagascar 
ment, rather than simply science, MCD offers opportunities to conservationists that few peer-reviewed journals can match. As the country progresses with its Durban Vision and ambitious goal of simultaneously conserving biodiversity whilst promoting its sustainable use for poverty alleviation and development, such opportunities should not be overlooked. Ensuring that Madagascar meets its conservation and development goals is an enormous challenge, but one that can be lessened if the diverse actors involved make the effort to share their experiences and learn from those of others. I look forward to editing many more such experiential contributions over the coming years.

Charlie J. Gardner

Durrell Institute of Conservation and Ecology (DICE), University of Kent and WWF Madagascar and Western Indian Ocean Programme Office cg235@kent.ac.uk

\section{REFERENCES}

Arlettaz, R., Schaub, M., Fournier, J., Reichlin, T. S., Sierro, A., Watson, J. E. M. and Braunisch, V. 2010. From publications to public actions: when conservation biologists bridge the gap between research and implementation. Bioscience 60, 10: 835-842. (doi:10.1525/bio.2010.60.10.10)

Cook, C. N., Hockings, M. and Carter, R. W. 2010. Conservation in the dark? The information used to support management decisions. Frontiers in Ecology and the Environment 8, 4: 181-186. (doi:10.1890/090020)

Fazey, I., Fazey, J. A., Salisbury, J. G., Lindenmayer, D. B. and Dovers, S. 2006. The nature and role of experiential knowledge for environmental conservation. Environmental Conservation 33, 1: 1-10. (doi:10.1017/ S037689290600275X)

Gardner, C. J. 2012. Social learning and the researcher-practitioner divide. Oryx 46, 3: 313-314. (doi:10.1017/S0030605312000737)

Harris, A. 2007. "To live with the sea": development of the Velondriake community-managed protected area network, southwest Madagascar. Madagascar Conservation \& Development 2, 1: 43-49. (doi:10.4314/ mcd.v2i1.44129)

Hulme, P. E. 2011. Practitioner's perspectives: introducing a different voice in applied ecology. Journal of Applied Ecology 48, 1: 1-2. (doi:10.1111/ j.1365-2664.2010.01938.x)

Milner-Gulland, E. J., Fisher, M., Browne, S., Redford, K. H., Spencer, M. and Sutherland, W. J. 2010. Do we need to develop a more relevant conservation literature? Oryx 44, 1: 1-2. (doi:10.1017/S0030605309991001)

Pullin, A. S. and Knight, T. M. 2005. Assessing conservation management's evidence base: a survey of management-plan compilers in the United Kingdom and Australia. Conservation Biology 19, 6: 1989-1996. (doi:10.1111/j.1523-1739.2005.00287.x)

Rabearivony, J., Fanameha, E., Mampiandra, J. and Thorstrom, R. 2008. Taboos and social contracts: tools for ecosystem management - lessons from the Manambolomaty Lakes Ramsar site, western Madagascar. Madagascar Conservation \& Development 3, 1: 7-16. (doi:10.4314/mcd.v3i1.44130)

Richard, A. F. and Ratsirarson, J. 2013. Partnership in practice: making conservation work at Bezà Mahafaly, southwest Madagascar. Madagascar Conservation \& Development 8, 1: 12-20. (doi:10.4314/mcd.v8i1.3)

Smith, R.J., Verissimo, D., Leader-Williams, N., Cowling, R.M. \& Knight, A.T. (2009). Let the locals lead. Nature 462: 280-281. (doi:10.1038/462280a)

Sunderland, T., Sunderland-Groves, J., Shanley, P. and Campbell, B. 2009. Bridging the gap: how can information access and exchange between conservation biologists and field practitioners be improved for better conservation outcomes? Biotropica 41, 5: 549-554. (doi:10.1111/ j.1744-7429.2009.00557.x)

Waeber, P. and Hänni, D. 2006. Combining conservation \& development. Madagascar Conservation \& Development 1, 1: 2. 